\title{
Investing in mutual funds: are you paying for performance or for the ties of the manager?
}

\author{
Costas Siriopoulos $^{1}$ and Maria Skaperda ${ }^{2}$
}

\begin{abstract}
This study analyses the performance of US Mutual Funds, from the perspective of Long Memory (LM), exploring if the returns of MFs are systematic due to their active management or they are random. The sample was 200 US equity MFs, from four categories, Large Cap, Middle Cap, Small Cap and World Stock, both 1- and 5-stars rating funds according to Morning Star rating. The time period was starting between 1981 and 2006 and ending 2016. Rescaled Range Analysis (R/S) employed for the Hurst exponent estimation, so to detect LM. Using Surrogate Data Analysis (SDA), the study was extended to Hurst exponent estimation for surrogate time series. The findings suggest that the selection of a MF presents a lot of complexity for investors. The 5-star MFs, with high qualified, and so expensive managers, tend to achieve random returns, while the returns of 1-star MFs, are more systematic. These MFs have higher fees than the 5-star MFs, but the management fees paid are quite inferior. This leads to the conclusion, that it might be preferable to pay for gaining an almost the same, but systematic return than to pay for the ties of the manager.
\end{abstract}

JEL classification numbers: G11, G24, C53

Keywords: Hurst exponent, Rescaled Range Analysis, Long Memory, Surrogate Data Analysis, Bootstrap, Mutual Fund Performance, Morning Star.

\section{Introduction}

Mutual funds offer numerous benefits to investors, including professional management, investment diversification, easy access to their money and convenience. However, the fee structure of mutual funds is not the same across funds and managers, and as a result fee structure and the costs of some funds will impact investors' return more than others. Mutual Funds Industry has taken a vigorous arise since 1990's which is retained till nowadays. Most of the recent growth has come in assets invested in equity mutual funds. At the end of August 2000, equity funds held more than $60 \%$ of all MF's assets, or more than $\$ 4.5$ trillion. The Investment Company Institute (ICI) estimates that, as at 2006, there were 61,855 funds with $\$ 21,808,884$ billion in total assets. By 2012 , this had increased to 73,243 funds with $\$ 26,837,407$ billion in total assets. The US mutual fund markets with combined assets of $\$ 18.9$ trillion under management at year-end 2016 remains the largest in the world (47\% of the regulated open-end fund assets worldwide). At the end of 200869,032 mutual funds are recorded with more than $\$ 22$ trillion under management worldwide ${ }^{3}$. Around one third is invested in equity mutual funds. This trend invigorates the need of

\footnotetext{
${ }^{1}$ College of Business, Zayed University, U.A.E.

${ }^{2}$ Department of Business Administration, University of Patras, Greece

${ }^{3}$ Source: http://www.icifactbook.org/.
} 
investors to use mutual funds for diversification and risk-management purposes. In fact, empirical evidence after the financial crisis of 2007-2008 suggests that the crisis had a noticeable impact on the volatility and liquidity of the markets and led to a new interest in questions of economic instability (Aigner et al 2018). Thus, the large academic literature and professional advises on mutual fund performance is not surprising (Papadamou and Siriopoulos 2004, Koulis et al. 2011, Das and Rao 2013, Kenchington et al. 2019)

The analysis of the fund performance is very important for professional analysts and portfolio managers, as well as for finance researchers and regulators. The main question that arise is whether the returns of the MFs are persistent, due to their active management or they are due to randomness. Given that investing in MFs is usually capital intensive and while have many expenses, primarily manager fees, especially for the high rated MFs, is very important to evaluate the active management according to its persistence of fund manager performance. Further, management fees are determined based on what other MF in comparable funds, regardless of performance, are being charged with implication on the demand for mutual funds. This creates a natural disconnect between fees and returns. In addition, management fees often reflect past performance, not current or expected performance. The asset-weighted average expense ratio across Morning Star funds was $0.57 \%$ in 2016, down from $0.61 \%$ in 2015 and $0.65 \%$ in 2013. This decline also shows the strong investor demand for lower-cost funds, and particularly applies for passive funds and institutional funds such as pension funds.

The largest component of a MF's overall expense ratio is portfolio management fee. For example, at the end of December 2012, the mean value of these fees was more than 0.58\% (Driebusch, WSJ, March 2013). The fees involved vary broadly across the spectrum of mutual funds and are one of the major drawbacks to these asset classes of investments. Although MF expense ratios follow a slightly decreasing trend because of economies of scale, of the general improvements in financial sector productivity, and the competition among MF sponsors, they remain very high - from 1,730 million in 2010 to 2,053 million in 2016 - due to the investors' migration to lower-costs funds and not from fee cuts by the fund management industry. For instance, Elton et al (2019) reported evidence that (while not statistically significant), expenses have an important impact in explaining the differential performance of ETFs (and less for index mutual funds), estimated that an increase of $1 \%$ of expenses may decrease the gross return for EFTs by 27 basis points per year.

In the mutual fund industry, pay for performance, is a model that offers financial incentives to MF companies and managers for achieving higher returns compared to their peers. Thus, management fees convey information about the costs of management to achieve higher returns and bear evidence about demand from investors to managers. Therefore, MF expenses are considered as a predictor of mutual fund performance.

In general, investors' willingness to pay for higher performance exceeds the cost of management. Therefore, investors receive a greater return as long as the management fees are lower. The question of what kind of pay for what kind of performance, however, becomes much more complex, suggesting further examination. In this paper we provide empirical evidence for answering the key question: are the returns of the MFs persistent, due to their active management skills, or they are random?

Though, most studies on performance persistence among mutual funds confirm that, on average, mutual funds have inferior performance to passive investment strategies. Most of the papers conclude that, in the short-term MF returns are persistent and that the significance of persistence decreases with the length of time horizon. Most of these studies investigate performance persistence at different time horizons using alphas obtained from a factor models as a measure of performance and apply both parametric and non-parametric statistical tests. It is evident that the heterogeneity of the used sample and 
the various statistical methodologies applied has led to many different results and the puzzle of mutual funds' performance persistence is not answered.

In recent studies (Papadamou and Siriopoulos 2004, Das and Rao 2013, Papadamou et al 2017) empirical evidence is provided that active management does not add significant value to the mutual fund performance and that mutual funds do not outperform benchmarks by as much as 75 basis points (Elton et al 2019). Although no longer new to the academy, revisiting this framework is particularly appropriate because we are now experiencing a re-evaluation of the mutual funds industry, supported by a growing number of empirical studies in both developed and emerging markets that have provided evidence against the superiority of active management. As a result, historical performance, although part of the evaluation process, is, at least in the mutual fund business, no longer regarded as the only driving feature in manager evaluations, and the importance of performance-related compensation schemes is gaining increased interest. Although not directly performance-based, such schemes reward the relative performance of asset managers indirectly, with the nexus between performance and fund management fees. Therefore, the investigation as of whether management fees are positively related with the performance of mutual funds is in the core of investors, mutual funds industry, and regulators interests. Our research work aims to answer this question by studying long memory effect and estimating Hurst exponent for surrogate time series.

Surprisingly little empirical research has been done on how investors consider expenses when investing in mutual funds, and in particular the fee-performance relationship. Only few empirical works are found, Sirri and Tufano (1998), who document a negative relation between fund flows and total fund expenses and Barber et al (2005), who document negative relations between fund flows and fund fees but no relation between fund flows and operating expenses. Hence, the selection of a MF presents a lot of complexity for investors. In this paper we are exploring if the returns of MFs are systematic due to their active management or they are random. We fill this gap in the empirical literature by analyzing 200 US equity MFs, from four categories, Large Cap, Middle Cap, Small Cap and World Stock, both 1- and 5stars rating funds according to Morning Star rating for the period 1981 through 2016. In particular, 200 equity US Mutual Funds performance is analysed from the perspective of Long Memory (LM) and Rescaled Range Analysis (R/S). Using Surrogate Data Analysis (SDA), the study was extended to Hurst exponent estimation for surrogate time series. Our results are also important because they reveal that the expensive managers of the high qualified 5-star MFs tend to achieve random returns, while the returns of 1-star MFs, are more systematic. These MFs have higher fees than the 5-star MFs, but the management fees paid are quite inferior. This leads to the conclusion, that it might be preferable to pay for gaining an almost the same, but systematic return than to pay for the ties of the manager.

The structure of the paper is as follows. Next section presents a literature review on Mutual Fund persistence. Section 2 discusses the Data and section 3 the methodology. In section 4 we present the empirical findings while section 5 concludes the paper with the major findings.

\section{Literature review on MF performance persistence}

The persistence of mutual fund returns has been a subject of much debate in the academic literature since investors base their fund selection procedure on the fund's prior performance (Sirri and Tufano 1998, Capon et al. 1996), although bestowing to the Myners' Report (2001) "selecting managers according to past performance figures first and brand second is widely acknowledged to be a poor way to select a manager". Past performance is not a guarantee for future returns as managers with above benchmark returns in one period are facing the same probability to have above or below benchmark returns next period.

The seminal studies of Treynor and Mazuy (1966) and Jensen (1967), gave rise to many researchers who analyse the performance of the fund, in order to distinguish the MF who over/under perform a 
benchmark. So, the issue of performance persistence has been widely researched in the context of mutual funds, hedge funds and pension funds, nevertheless the results are mixed and unclear over short-term and long-term horizon for various markets, different time periods and fund styles.

Griblatt and Titman (1992) study MF returns over the 1975-1984 period and find evidence of performance persistence over five years, attributing this result to managerial skills. Hendricks et al. (1993) studying the period 1974-1998 provide evidence of MF persistence over a short-time horizon to one to three years and attribute this persistence to "hot hands" phenomenon or common investment strategies. Brown and Goetzmann (1995) examine the performance persistence of US mutual funds and claim that the persistence is mostly due to funds that lag the S\&P. They also demonstrate that relative performance pattern depends on period observed and is correlated across managers, suggesting that that persistence is probably not due to individual managers, which is consistent with herding theories of behavior.

Malkiel (1995) finds that whilst performance persistence existed in the 1970s, there was no consistency in MF returns in the 1980s, and Carhart (1997) provides evidence of persistence in MF's returns for the period 1962-1993. Brown, Draper and McKenzie (1997) examine the consistency of UK pension fund performance for the period 1981-1992 and find "limited evidence of persistence in performance" for a small number of fund managers. They find that this limited consistency holds over different time horizons, samples and classification schemes, though this finding seems to be influenced by the manager-outlier. Thomas and Tonks (2001) and Tonks (2002) analyzed the performance of UK pension funds over the period 1983-1997 and found evidence of persistence in abnormal returns generated by fund managers over one-year time horizon but limited evidence of persistence at other time intervals. However, their study does not consider the costs of fund management. Hence, it is not clear whether abnormal returns outweigh the costs of fund management.

Papadamou and Siriopoulos (2004) studied American no-load equity mutual funds that invest in European stocks and keep their managers for more than three years, in order to investigate the persistence of the short-term performance, and the related investment style. Their results showed an underperformance compared to the Eurostoxx index and a 'hot hands' phenomenon does not persist, with some exceptions. Capocci et al. (2005), analyze the persistence of hedge fund performance in bull and bear markets, and document that there exists limited evidence of performance persistence since most of the predictability of superior performance is to be found only during the bull market period. Hereil et al (2010) also provide evidence that the persistence of the performance of US mutual funds is relatively poor with respect to the time horizon of investors and conclude that that past performance and ratings cannot be the only criteria to be considered when choosing to invest in mutual funds.

These, and other studies find only limited evidence of performance persistence and the attribution of this evidence also differentiate. Thus, literature research on persistence in MF returns has evidenced conflicting results and there is no consensus on this issue. In addition, not all of these studies report evidence whether the fund managers with the persistent performance are charging fees that reflect his/her abilities. In addition, although many studies report statistically significant returns, the economic significance of persistence of the returns of mutual funds is questionable. If we take under consideration the mutual fund expenses, a simple buy-and-hold strategy might be proved superior to active management. In a recent report of Morningstar (2016) it is reported that the relative performance in the short-term in equity mutual funds is due to the momentum of stocks, rather than in manager skills, and over the long-run "there is no meaningful relationship between past and future fund performance". So, why investors are paying high fees for active management fund?

In fact, few studies have been done on how investors consider expenses when investing in mutual funds. The paper of Sirri and Tufano (1998), who document a negative relation between fund flows and total fund expenses, and that of Barber et al (2005), who document negative relations between fund flows 
and fund fees but no relation between fund flows and operating expenses for the period 1970 to 1999. Elton et al (2019) study EFTs and index mutual funds and find that picking the lowest expense index fund improves return by 33 basis points in the next year for institutional investors or 38 basis points per year for retail investors (for ETFs, the difference is much lower per year due t the fact that there are fewer choices). They also report that the lowest expense funds have the highest performance of all alternatives in the next period.

Thus, there are only few papers studying the performance persistence of mutual funds in relation to management fee structure. In our paper we fill this gap in the empirical literature by studying performance persistence of mutual funds in relation to management fee structure.

An average, risk-averse, investor care about both risk and return though. Busse (1999) predicts that MF managers should time volatility counter-cyclically, that is they tend to decrease (increase) fund systematic risk when conditional market volatility rises (falls). Giambona and Golec (2007) show that management fees are positively correlated with the level of fund risk, and that higher MF fees are associated with less counter-cyclical, or more pro-cyclical, volatility timing, which can vary across funds with various fees schedules. So, the persistence of returns is of major concern for investors to choose the appropriate MF in relation to the associated fees and variability of returns. It is also important for capital market authorities when regulate MF regarding the disclosure of MF fees structure to the investors. Still, these studies do not answer a fundamental question about the randomness of the manager's performance associated with the fee schedule of MF.

In conclusion, the heterogeneity of previous studies has led to many different results, which may be produced by different databases, investigation periods, performance measures, and statistical methodologies (Eling 2009 for an excellent literature review on the subject). As Eling (2009) states "... the use of different methodologies is one of the key reasons for the unsteady results found in literature".

To our best knowledge, the only paper studying long term behaviour of MF's returns is Doncel et al. (2009). The authors use Detrended Fluctuation Analysis (DFA) in order to examine persistence in MF, using bootstrap techniques, in the Spanish market. However, Surrogate Data Analysis (SDA) is preferable to Bootstrap, for different reasons (Theiler et al. (1992), Schreiber and Schmitz (2000)). This is because basic properties of the original time series (such us mean and variance) are preserved without leaving room for further structure in our original data. Thus, "the surrogate data is then generated to mimic these preserved features but otherwise to be random" (Theiler et al. (1992)).

This means that SDA is different to the Bootstrap as it refers to a constrained randomization simulation-based hypothesis testing framework, found in permutation tests (Leontitsis and Vorlow, 2005). Among SDA Algorithms, the IAAFT and Shuffle are preferable, because the first one preserves the power spectra of the original data and approximates well the original linear correlations, but is time consuming, and the second is the simplest way to make surrogate time series (Leontitsis and Vorlow (2005), Kugiumtzis (2000) and Leontitsis (2003)).

\section{Data and methodology}

The sample comprises of 200 equity MFs. The 184 of them are US equity (Stock funds with at least $70 \%$ of assets in U.S. stocks) and 16 World Stock Funds (these portfolios typically have $20 \%-60 \%$ of assets in U.S. stocks) over the period 1981-2016. The data were obtained from Yahoo Finance. In order to exclude biases to the results such us size and performance, the selection was made from four MF categories, Large Cap, Middle Cap and Small Cap (comprising of Value, Growth and Blend Funds, in each category, according to the Morning Star) and World Stock, both on top and bottom 10\% of the performance, i.e. we used 5 and 1 stars rating funds according to backward-looking Morning Star rating, based on a fund's past risk and load-adjusted returns versus category peers. 
The fee structure appears on the MF's prospectuses, however, they are hidden or obscured with complex and technical language, and the average investor does not recognize what is paying for. In addition, there is a part of ongoing fees that are not specified on investor's account statement. These are the "Annual Fund Operating Expenses" and costs, such as investment advisory fees for managing the fund's holdings, and marketing and distribution expenses, as well as custodial, transfer agency, legal, accounting, and other administrative expenses. For instance, a MF with a high turnover ratio or investing in illiquid or exotic markets typically face higher such costs, which are usually not reported. Therefore, these costs are easily camouflaged by the volatility of returns which are positively correlated with management fees (Golec 1992). And these fees and expenses really add up over time with a negative impact on investor's portfolio. In our sample, the most 1-star MFs have higher expense ratios than the 5star MFs, as shown in Figure 1.

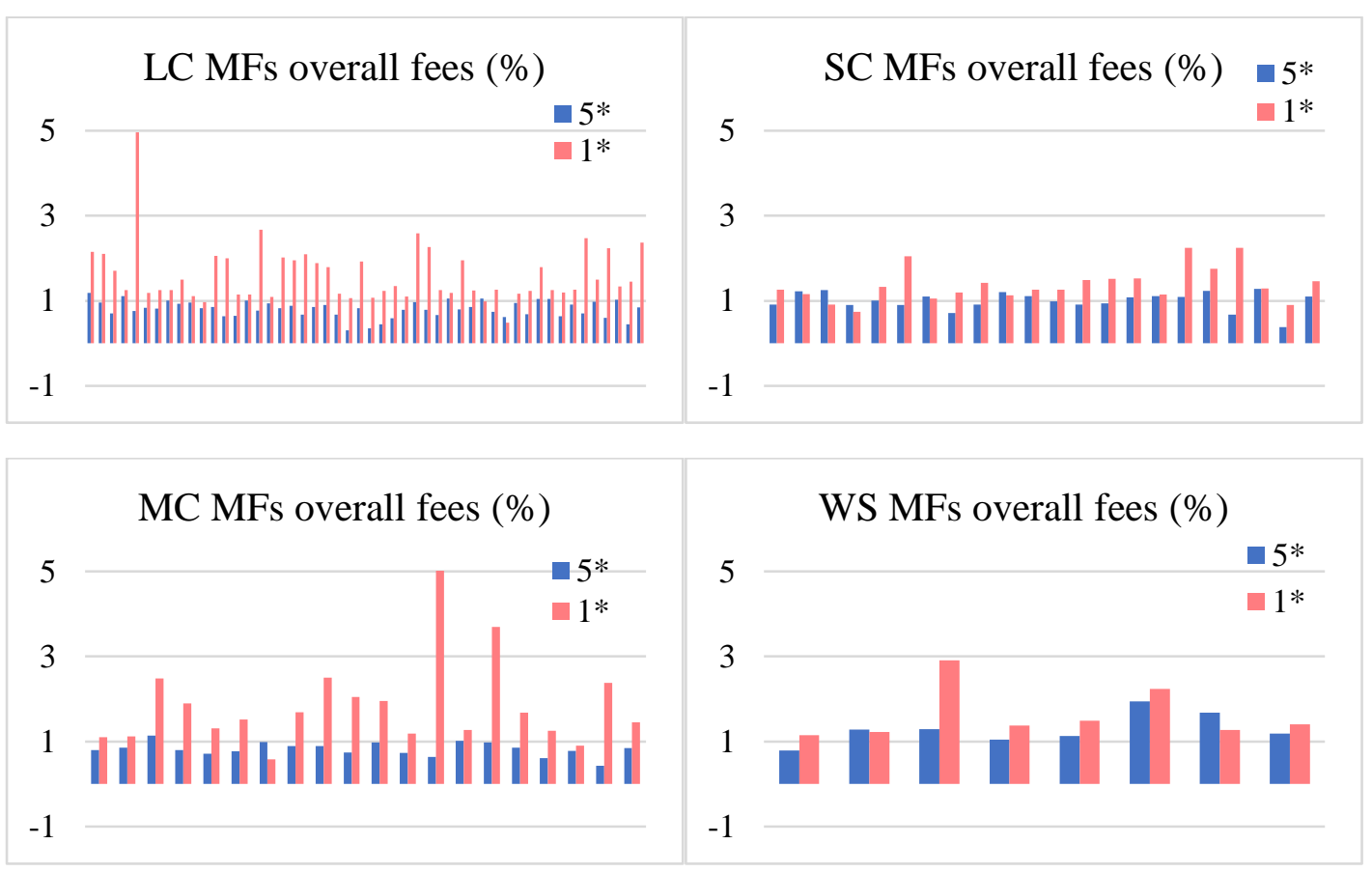

Figure 1: Overall fees of the different categories of MFs

The MFs of our sample are further classified, in different types, according to their expense ratios. For example, from type A, (front-load MF with $12 \mathrm{~b}-1$ expenses, $0.25 \%$ ) to type I (no load, $0 \%$ for $12 \mathrm{~b}-1$ expenses), all including management fees. Most expensive MFs are those of class A. However, private investors cannot usually withstand requirements of low cost MFs, such us of class I (Institutional), that have very high minimum investing requirements. Institutional funds refer to funds that aim to manage money for large institutional investors. In general, most capital market authorities have categorized the wrap fees of all types, imposing upper rates for every fee category. For instance, SEC, for the I-type category, Large Cap, granted a flat fee of $0.70 \%$. Unlike the expense ratios, MFs of class I have higher management fees than the class A MFs. Table 1 shows the percentage of Management fees to overall fees (annual report at the end of 2015) for the sample. 
Table 1: Average management fees as a perventage of total fees for 5-star and 1-star mutual funds.

\begin{tabular}{|l|c|c|}
\cline { 2 - 3 } \multicolumn{1}{c|}{} & \multicolumn{2}{c|}{ Average management fees/total fees } \\
\hline MF category & 5 stars & 1 star \\
\hline Large Cap (LC) & $74.96 \%$ & $53.81 \%$ \\
\hline Middle Cap (MC) & $80.77 \%$ & $54.90 \%$ \\
\hline Small Cap (SC) & $77.74 \%$ & $65.74 \%$ \\
\hline World Stock (WS) & $54.70 \%$ & $55.04 \%$ \\
\hline
\end{tabular}

Most MFs in 5 stars rating are of type I and in 1-star rating, are of type A, as it is shown in the following diagrams. This means that the most 1-star MFs have higher expense ratios.

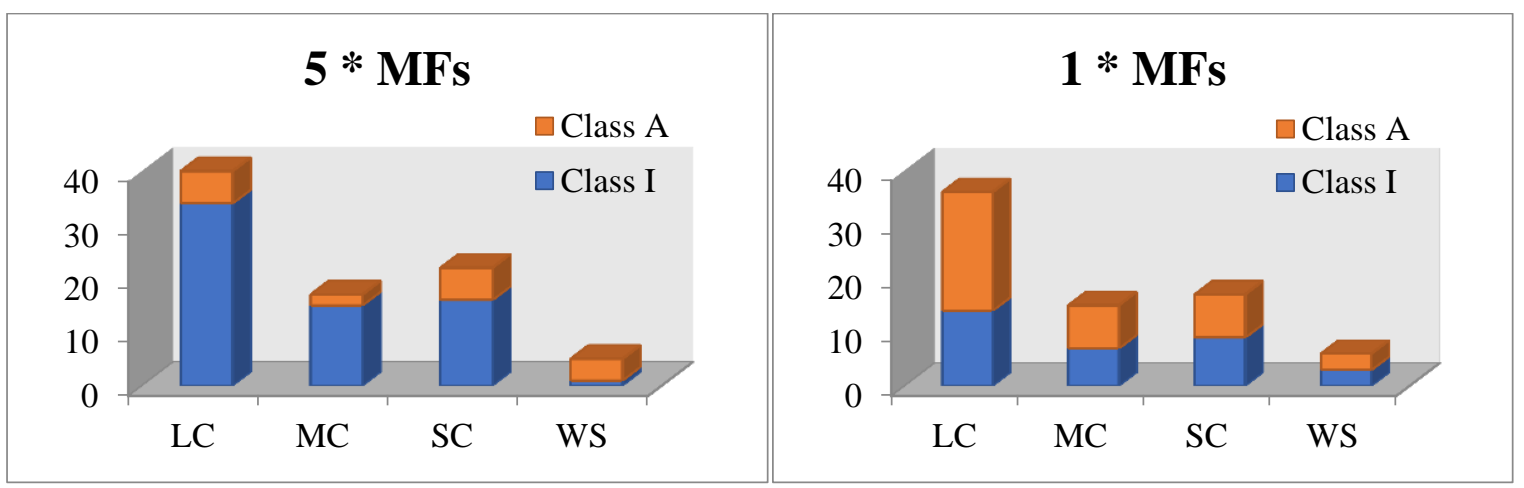

Figure 2: Expense ratios for 5-star MFs (left side) and 1-star MFs (right side)

Our series include MFs with different time range, starting between 1981 and 2006 and ending 2016. Daily NAV (Net Asset Values) net of commissions and other expenses were used. Augmented Dickey Fuller test (ADF) (Dickey Fuller 1979), was employed and found that our series are I(1). Thus, we proceeded our methodology using first differences.

\subsection{Methodology}

The key research question of the study is if the returns of MFs are persistent due to their active management or they are random. To achieve this, we estimate Long Memory, which denotes the property of a time series to exhibit a significant dependence between very distant observations. In this respect, we estimate the Hurst exponent for our time series, employing Rescaled Range Analysis (R/S), as recommended by Hurst (1951), Mandelbrot (1972) and Greene and Fielitz (1977). 
The basic idea behind the classical R/S test is to compare the minimum and maximum values of running sums of deviations from the sample mean, renormalized by the sample standard deviation. So for a time series $\mathrm{x}_{\mathrm{t}}(\mathrm{t}=1, \ldots, \mathrm{T})$, we consider a sample of $\mathrm{k} \mathrm{N}$-dimensional sub-vectors, such as $\mathrm{T}=\mathrm{k}^{*} \mathrm{~N}$.

Let $\bar{x}_{k}=\frac{1}{N} \sum_{i=1}^{N} x_{i, k}$ the mean value of every sub-vector.

Define the aggregated time series as $Y_{t}=\sum_{j=1}^{t} x_{j}$. Choosing sub-vectors of length $\mathrm{n}$ we can define the adjusted range statistic as:

$$
R(t, n)=\max _{0 \leq i \leq n}\left[\left(Y_{t+i}-Y_{t}\right)-\frac{i}{n}\left(Y_{t+n}-Y_{t}\right)\right]-\min _{0 \leq i \leq n}\left[\left(Y_{t+i}-Y_{t}\right)-\frac{i}{n}\left(Y_{t+n}-Y_{t}\right)\right]
$$

1. For every sub - period calculate the widest difference in the series off deviations.

2. Calculate the standard deviation for each range and repeat the process for each sub-period. Next, the length of sub periods is increased and the whole process is repeated.

3. Get the average rescaled ranges for each sub-period in the time series

4. Rescale Range then scales as $\quad(\mathrm{R} / \mathrm{S}) \approx \mathrm{cn}^{\mathrm{H}}$

Where $\mathrm{c}$ is a finite constant independent of the length of sub-period. $\mathrm{H}$ is the Hurst exponent.

5. To uncover the scaling law, we use OLS regression on logarithms of each side of (1). Thus, we get:

$$
\log (\mathrm{R} / \mathrm{S})_{\mathrm{n}}=\log (\mathrm{c})+\mathrm{H} \log (\mathrm{n})
$$

Hurst $(\mathrm{H})$ statistic is used as a measure of classifying a time series based on its long-term dependencies whereby an $\mathrm{H}$ of 0.50 indicates a series is random. A $0<\mathrm{H}<0.5$ indicates an anti-persistent series, suggesting the data set exhibits mean reverting tendencies, while a $0.5<\mathrm{H}<1$ designates a persistent series, suggesting the data is trend reinforcing.

Furthermore, the analysis involved time series computed from the original, using Surrogate Data Analysis (SDA) resulted from the Shuffle Algorithm. Given a time series $x_{t}(t=1, \ldots, T)$, one can make shuffled surrogates $b$ randomly intermixing its values with respect to their temporal order (Theiler et al 1992, Schreiber \& Schmitz 1996). The artificial data sets preserve the distribution characteristics of the original data (mean and variance) and exhibit the same spectral properties (power spectrum and auto correlation function). Following Theiler et al (1992), we calculated the p-values of surrogates for onetailed test and the results indicated that the irregularity of the original data is most likely due to random inputs to the systems. Moreover, we compared the two distributions (observed data and surrogate) directly, using Kolmogorov-Smirnoff test. In all of our series the null hypothesis that the two dataset values are from the same continuous distribution was accepted.

\section{Empirical Findings}

Our results for the 5 stars MF's indicated that R/S analysis overestimate the Hurst exponent in case of the original series. Only 3 of the total $200 \mathrm{MFs}$ of our sample have $\mathrm{H}<0.5$, (Figure 3, top charts). These values are not taken into account, as they result of noisy data. 
When we perform SDA (shuffle) in our series the percentage of MFs that exhibit antipersistent behaviour, increases. The phenomenon is more intense at the 5 stars MFs (up to 35\%) which have higher management fees (Figure 3, bottom left chart). This means that returns are not long memory processes and thus they are not persistent. In that case, the management fees are expensive. It is worth to note that these MFs do not change frequently their fund manager, who is highly qualified, according to Morning Stars criteria. Thus, an investor is "paying for the ties of the manager" rather than for performance of the MF.

Contrary, the 1-stars MFs exhibit long memory properties to a greater extent than the 5 stars MFs (up to $80 \%$ ) and thus their performance is persistent. (Figure 3, bottom right chart). Any bias removed by SDA alter these results at lower rates than the 5 stars MFs.
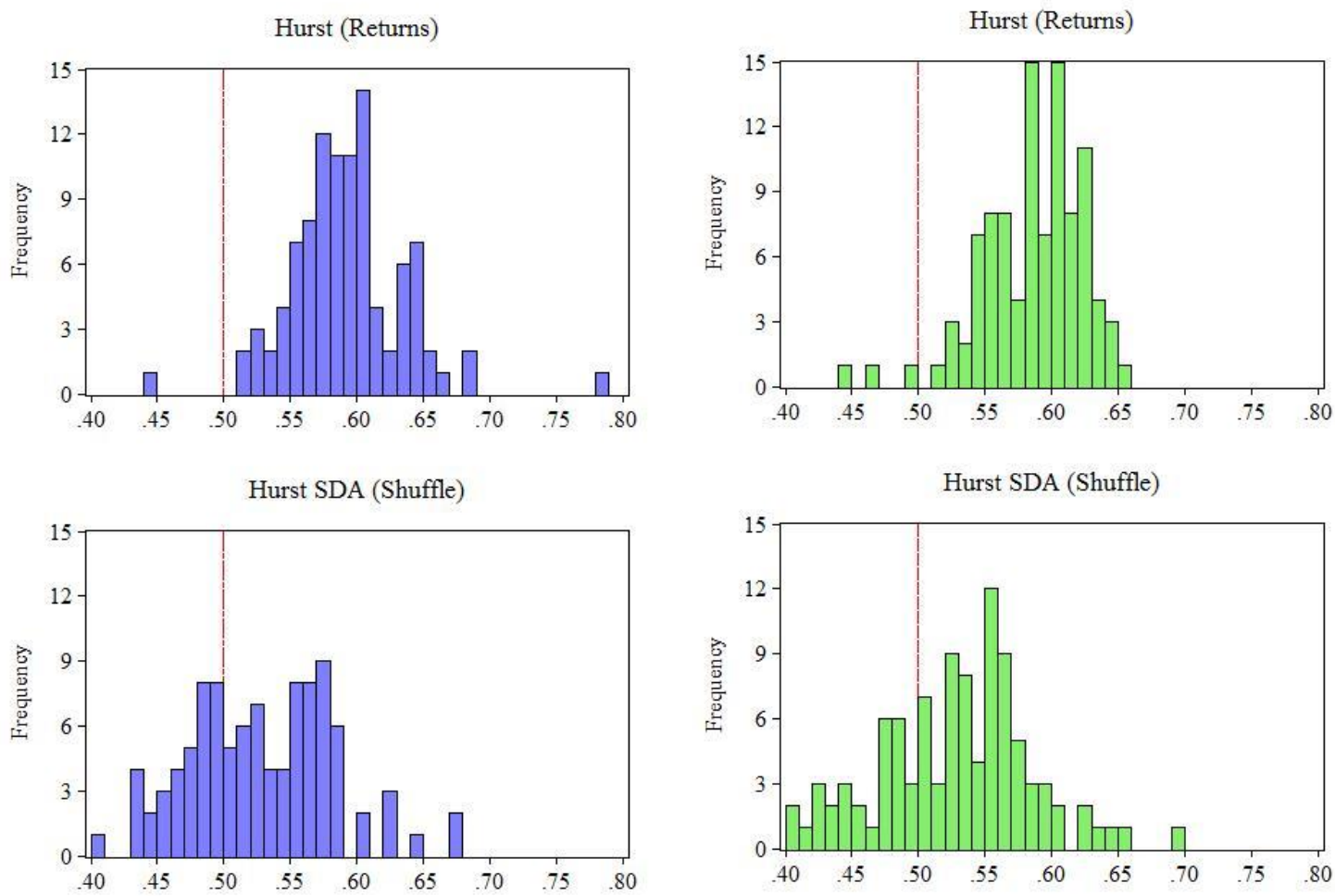

Figure 3: Hurst and Hurst SDA distributions for 5 stars and 1 star MFs

Note that most of the 1 star MFs tend to hire fewer expert managers based to Morning Stars criteria. Although these MFs have higher overall fees than the 5-stars MFs, the management fees paid are quite inferior comparing to those paid to the 5 stars MFs and the investors pay for persisting returns. This could be considered "value for money".

It is not only interesting, but also important to compute the positive over negative returns during the time span of each MF. For example, for the 5 stars Large Cap MFs the positive returns during the life time studied ranged from $44 \%$ to $47 \%$ approximately. For the 1-star Large Cap MFs, the respective range was $48 \%$ to $54 \%$. The corresponding result for the Small Cap 5 stars MFs, was about 47\%, though for the Small Cap 1-star MFs was $48 \%$ approximately.

The findings clearly suggest that the selection of a MF presents a lot of complexity for investors. So far, we know that past performance is not a guarantee for future returns, (Lückoff, 2011). The evidence 
indicated that both the image of the MF Company and the high qualifications of the manager, present also unsafety towards to relevant investment. This leads to the conclusion that it might be preferable to pay for gaining an almost the same, but persistent return than to pay for the «ties of the manager». Another implication of our results is that good managers are very hard to find and are worth every penny they are paid.

The findings are important for marketing purposes of MF Companies. By signifying the advantages of the 1-star MF's, the results are also valuable for portfolio diversification purposes and asset managers when they include MF's as an asset class in their portfolios. As a last note, these results could have implications for the regulators who should explore in more depth the persistence of the MF performance, when they normalize MF market.

\section{Conclusion}

Capital market authorities force mutual funds to contain the warning that past performance is not a guarantee for future returns. Nevertheless, for most investors track record is the focal criterion to allocate capital to different funds, expecting that past performance will persist over time. This study analyses the persistence of the performance of US Mutual Funds, from the perspective of Long Memory (LM), and exploring if the returns of MFs are systematic due to their active management or they are random.

Our findings indicated that both the image of the MF Company and the high qualifications of the manager present also unsafety towards to relevant investment. In particular, we documented that an average investor is "paying for the ties of the manager" rather than for performance of the MF. These findings might have implications for the regulators who should explore in more depth the persistence of the MF performance, when they normalize MF market. Our results are in line with the findings of Barber et al (2005) and suggest that mutual funds should "disclose to investors the actual dollar amount of fees paid". In addition, the existing the hegemony of past performance as the only factor affecting investors' decision as to which fund to choose has been questionable and criticized for potentially skewing investors' decisions towards the best-performing funds and paying higher fees.

Overall, the results strongly indicate that mutual fund investors should not base their choice on past performance alone when selecting which fund to invest in. Rather, they should combine performance analysis with the fund's fees, and to the overall quality of the fund's management team. Also, the mutual fund industry should move towards management fees as a fix percentage of assets under management, with fee structure differing across management styles and asset classes.

\section{References}

Aigner, E., M. Aistleitner , F. Glötzl and J. Kapeller (2018). "The Focus of Academic Economics: Before and After the Crisis", Institute for Ecological Economics, Department for Socioeconomics, Vienna University of Economics and Business, Working Paper No. 75.

Babalos V. et al. (2008). Testing for persistence in mutual fund performance and the ex post verification problem: Evidence from the Greek market. Europ. J. Fin., 14, pp. 735-753.

Barber, M. B., D. T. Odean L. Zheng (2005). Out of Sight, Out of Mind: The Effects of Expenses on Mutual Fund Flows, Journal of Business, 78(6), pp. 2095-2119.

Bollen N., J.A. Busse (2005). Short term Persistence in Mutual Fund Performance. Rev. Fin. Stud. 18, pp. 569-597.

Brown, S. and W. Goetzmann (1995). Performance persistence. Journal of Finance, 50, pp. 679-698.

Busse, Jeffrey A. (1999). Volatility timing in mutual funds: Evidence from daily returns, Review of Financial Studies 12, pp. 1009-1041. 
Capon, N., Fitzsimons, G. J., \& Alan Prince, R. (1996). An individual level analysis of the mutual fund investment decision, Journal of Financial Services Research, 10(1), pp. 59- 82.

Carhart, M., (1997). On persistence in mutual fund performance. Journal of Finance, 52(1), pp. 57-82.

Capocci, D., Corhay, A., \& Huber, O. R. (2005). Hedge fund performance and persistence in bull and bear markets. The European Journal of Finance, 11(5), pp. 361-392.

Das, P.K.; Uma Rao, S.P. (2013). Performance evaluation of socially responsible mutual funds using style analysis. Soc. Responsib. J., 9, pp. 109-123.

De Souza, C., \& Gokcan, S. (2004). Hedge Fund Investing: A Quantitative Approach to Hedge Fund Manager Selection and De-Selection. The Journal of Wealth Management, 6(4), pp. 52-73.

Driebusch C. (2013). Are High-Priced Managers Worth It? WSJ, March 1, 2013, http://online.wsj.com/articles/SB10001424127887323549204578320040256209154

Doncel L.M., P. Grau-Carles and J. Sainz (2009). On the long-term behavior of mutual fund returns. Quant. Fin., 9(6), pp. 653-660.

Eling, M. (2009). Does hedge fund performance persist? Overview and new empirical evidence. European Financial Management, 15(2), pp. 362-401.

Elton, E. J., Gruber, M. J., \& de Souza, A. (2019). Passive mutual funds and ETFs: Performance and comparison. Journal of Banking \& Finance, 106, pp. 265-275.

Engen E.M, A. Lehnert, R. Kehoe (2000). Mutual Funds and the U.S. Equity Market. Fed. Res. Bul., December, pp. 797-812.

Giambona, E., and Joseph Golec (2007). Incentive Fees and Mutual Fund Volatility Timing, Western Finance Meetings.

Golec, Joseph (1992). Empirical tests of a principal-agent model of the investor-investment advisor relationship, Journal of Financial and Quantitative Analysis, 27, pp. 81-95.

Greene, M.T. and B.D. Fielitz, (1977). Long-term dependence in common stock returns. J.Fin.Econ, 4(3), pp. 339-349.

Grinblatt, M. and Titman, S., (1992). The persistence of mutual fund performance. Journal of Finance, 47, pp. 1977-1984.

Hereil, P., P. Mitaine, N. Moussavi, and T. Roncalli (2010). Mutual Fund Ratings and Performance Persistence, https://ssrn.com/abstract=1749414 or http://dx.doi.org/10.2139/ssrn.1749414

Hurst, H.E., (1951). Long-term storage capacity of reservoirs. Transactions of the Amer. Soc. of Civil Eng., 116, pp. 770-799.

ICI, . http://www.icifactbook.org/

Ippolito, R., (1989). Efficiency with costly information: a study of mutual fund perfomance, 1965-84. $Q$. J. Econ., 104, pp. 1-23.

Jensen M. C. (1967). The Performance of Mutual Funds in The Period 1945-1964. Journal of Finance, 23(2), pp. 389-416.

Kenchington, D., Wan, C., \& Yüksel, H. Z. (2019). Gross profitability and mutual fund performance. Journal of Banking \& Finance, 104, pp. 31-49.

Koulis, A., Botsaris, C., Adam, M., \& Beneki, C. (2011). An assessment of the performance of Greek mutual equity funds selectivity and market timing. Applied Mathematical Sciences, 5(4), pp. 159171.

Kugiumtzis D. (2000). Surrogate Data test on time series. In "Nonlinear deterministic modelling and forecasting of economic and financial time series", A. Soofi and L. Cao (eds).

Leontitsis A. (2003). A note on Shuffled Financial Surrogates. Math. and Comp. Modeling, 38, pp. 33-40.

Leontitsis A. and C. Vorlow (2005). Accounting for outliers and calendar effects in surrogate simulations of stock return sequences. Physica A, 368(2), pp. 522-530.

Lückoff P. (2011). Mutual Fund Performance and Performance Persistence. The Impact of Fund Flows and Manager Changes. Eds. Gabler Verlag | Springer Fachmedien Wiesbaden GmbH.

Mandelbrot B.B., (1972). Statistical methodology for nonperiodic cycles: from the covariance to R/S analysis. Annals of Econ. Soc. Measurements, 1, pp. 259 - 290. 
Morningstar (2016). Performance Persistence Among U.S. Mutual Funds, January, Morningstar. http://www.fwp.partners/wp-content/uploads/2016/09/Performance-Persistence-Morningstar2016.pdf

Morningstar Manager Research (2017).

Papadamou, S., Kyriazis, N. A., \& Mermigka, L. (2017). Japanese mutual funds before and after the crisis outburst: A style-and performance-analysis. International Journal of Financial Studies, 5(1), 9.

Papadamou, S., and C. Siriopoulos (2004). American equity mutual funds in European markets: Hot hands phenomenon and style analysis, International Journal of Finance and Economics, 9, p.p. 8597

Schreiber T. and A. Schmitz, (1996). Improved surrogate data for nonlinearity tests. Phys. Rev. Let. 77 , pp. 635-638.

Sirri, E. R., \& Tufano, P. (1998). Costly search and mutual fund flows, Journal of Finance, 53(5), 15891622.

Theiler J. et al. (1992). Testing for nonlinearity in time series: the method of surrogate data. Phys. D. 58, 77-94.

Thomas, A. and I. Tonks (2001). "Equity Performance of Segregated Pension Funds in the UK", Journal of Asset Management, 1(4), pp. 321-343

Tonks, Ian (2002). Performance Persistence of Pension Fund Managers Centre for Market and Public Organization, University of Bristol, CMPO, http://www.bris.ac.uk/Depts/CMPO/

Treynor, J. and Mazuy, M. (1966). Can mutual funds outguess the market? Harvard Bus. Rev., 44, pp. $131-136$. 